\title{
Energy distribution of EHD emitted gold ions
}

\author{
P. Sudraud (*), C. Colliex and J. van de Walle \\ Laboratoire de Physique des Solides $\left({ }^{* *}\right)$, Université Paris-Sud, 91405 Orsay, France
}

(Reçu le 12 février 1979, accepté le 6 mars 1979)

\begin{abstract}
Résumé. - Les distributions en masse et en énergie d'ions Au émis par une source électrohydrodynamique ont été étudiées. Pour l'espèce ionique principale $\left(\mathrm{Au}^{+}\right)$la largeur énergétique est $65 \mathrm{eV}$ à $8 \mathrm{keV}$. Pour les autres espèces ioniques $\left(\mathrm{Au}_{n}^{+}, \mathrm{Au}_{n}^{++}\right)$d'importantes modifications de distribution énergétique ont été observées. Ces résultats confirment l'hypothèse selon laquelle la formation des ions est due à des processus de post-ionisation dans une couche de plasma dense couvrant l'apex du cône de Taylor.
\end{abstract}

\begin{abstract}
The mass and energy distributions of electrohydrodynamically emitted gold ions have been studied. For the main ionic species $\left(\mathrm{Au}^{+}\right)$a FWHM of $65 \mathrm{eV}$ has been measured at $8 \mathrm{keV}$. For the other ionic species $\left(\mathrm{Au}_{n}^{+}, \mathrm{Au}_{n}^{++} \ldots\right)$, large modifications of the energy distributions have been observed. All these experimental results support the general idea that the ion formation is generally due to post ionization processes in a dense plasma layer covering the apex of the emitting Taylor cone of liquid metal.
\end{abstract}

1. Introduction. - Among the solutions which are presently investigated for the achievement of highbrightness ion beams, electrohydrodynamic (EHD) ion sources seem very promising because they provide rather high currents (at least of the order of $10^{-4} \mathrm{~A}$ ) from relatively small areas. In this technique which is mostly applied to liquid metals, ions are generated from the extremity of the cone-shaped meniscus (Taylor cone) which is formed when an electrostatic field greater than a critical value is applied on the surface of a conducting liquid (Taylor [1]).

Though this ion production mode has been recognized for many years (Swatik and Hendricks [2], Mahoney et al. [3], Evans and Hendricks [4], Clampitt et al. [5], Krohn and Ringo [6]), relatively few data concerning the characterization of the ion species in the beam have been gathered until now. The results to date have not been sufficient to obtain a satisfactory understanding of the ion production mechanisms. There consequently exists a specific need for measurements of the energy distribution which is partly responsible for the size of many ion probes as a consequence of the chromatic aberrations of the probe-forming ion optics.

Previous reports have briefly mentioned FWHM of $12 \mathrm{eV}$ for $\mathrm{Ga}$ and $15 \mathrm{eV}$ for Cs (Krohn and Ringo [6]), $25 \mathrm{eV}$ for $\mathrm{Ga}$ (Mair and von Engel [7]), measured

$\left(^{*}\right)$ This paper covers part of the thesis work of P. Sudraud which will be held in Orsay (1979).

$\left.{ }^{* *}\right)$ Associé au C.N.R.S. by retarding potential techniques; they therefore concern the energy distribution of the total ion beam without referring these data to a given ion species. Similarly an indirect estimation of $14 \mathrm{eV}$ has been deduced by Seliger [8] from the observed size of the chromatically aberrated beam spot. On the other hand, larger values ranging from 60 to $100 \mathrm{eV}$ depending on the total emitted current have been determined by Swatik [9] for a gallium-indium ion source.

In this letter, more complete data concerning the energy distribution of EHD-emitted gold ions are shown, a preliminary report of which has been given at the 25th International Field Emission Symposium (Sudraud et al. [10]).

2. Experimental device. - 2.1 EHD SOURCE. A simple EHD ion source, the detailed design of which will be published elsewhere, has been built. In the present study, a film of molten gold wets a tungsten tip of rather large radius of curvature (about $10 \mu$ ). The free surface is distorted under the influence of an applied electrostatic field and, above a critical voltage $V_{c}$ depending on the source geometry, a stable conical equilibrium shape of semi-angle close to $45^{\circ}$ is reached as shown in figure $1 a$. This behaviour has been explained by Taylor [1] as a consequence of the balance between electrostatic and surfacetension forces. However, the exact radius of curvature of the extremity of this cone has not been determined satisfactorily (quoted values range from a few Angströms to a few hundreds of Angströms). 


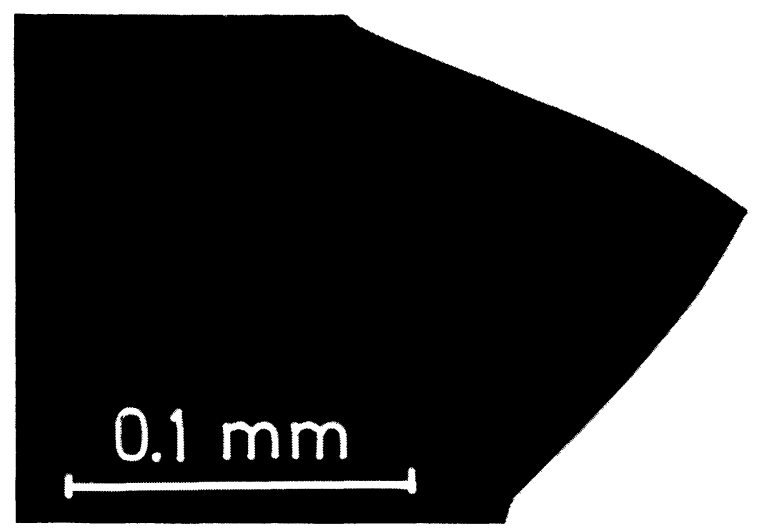

Fig. 1a. - Profile of a Taylor cone of liquid gold visualized after its solidification.

In a specifically designed electron microscope specimen holder (Colliex et al. [11]), a Taylor cone of liquid gold has been imaged in situ with the help of a TV camera and subsequent video tape recorder. In these extreme environmental conditions $(T \sim 1400 \mathrm{~K}$ and $V \sim 10 \mathrm{kV}$ ), the limited resolution prevents one from detecting details below typically $100 \AA$. The image shown in figure $1 b$ allows an estimate of a mean radius of curvature of about $3 \mu$. Though much uncertainty remains about the shape factor, the electrostatic field applied on the surface can be estimated to be of the order of $5 \times 10^{6} \mathrm{~V} / \mathrm{cm}$ at $8 \mathrm{kV}$ (a standard shape factor $\beta=5$ is assumed, and the real one for such a large semi-angle is likely greater) which is two orders of magnitude smaller than the pure evaporation field, as calculated by Tsong [12] $\left(F_{1}=5.3 \times 10^{8} \mathrm{~V} / \mathrm{cm}\right.$ for $\mathrm{Au}^{+}$and $F_{2}=5.4 \times 10^{8} \mathrm{~V} / \mathrm{cm}$ for $\mathrm{Au}^{++}$). Though the total emitted current can reach values as high as $1 \mathrm{~mA}$ for a single tip, voltage and temperature conditions have been chosen rather close to the onset ones, so that the total emitted ion current is about $100 \mu \mathrm{A}$. This threshold current $(\sim 100 \mu \mathrm{A})$ at the onset voltage seems actually higher for gold than for the low melting point metals previously studied by other authors. (Krohn and Ringo quote values of $1 \mu \mathrm{A}$ for $\mathrm{Cs}$ and $\mathrm{Ga}[6])$.

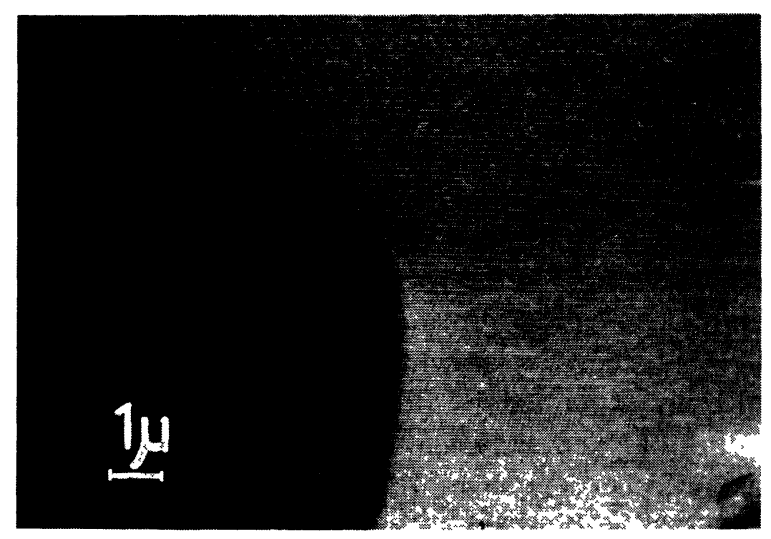

Fig. 1b. - In situ electron microscopic observation of the extremity of a Taylor cone of liquid gold during the EHD emission.
2.2 BEAM ANALYSIS SYSTEM. - A reduced fraction of the emitted beam is collected through the entrance aperture of a high resolution double focussing mass spectrometer (Nier-Johnson system). The original design has been modified to take advantage of the energy analytical properties of the electrostatic sector. For a given mass defined at the exit of the magnetic system, the energy distribution is scanned in front of an aperture located at the first cross over between the electrostatic and magnetic units by superposing a calibrated voltage ramp over the primary one (Colliex et al. [13]). Both functions (high voltage scanning and data collection in a pulse counting mode) are achieved with the help of a computer-aided system which has been used for similar energy distribution measurements of transmitted electrons in electron microscopy (Trebbia et al. [14]).

3. Results. - For each mass peak detected, the energy spectrum is displayed as a distribution of counts in energy channels. The summation of the signals over the energy ranges leads to the determination of the mass distribution.

3.1 Mass Distribution (Fig. 2). - A large variety of ionic species has been detected ranging from singly or doubly ionized atoms to molecular ions with one or two charges. The most abundant ones are respectively the $\mathrm{Au}^{+}$(about $65 \%$ ) and $\mathrm{Au}^{++}$(about $20 \%$ ) ions.

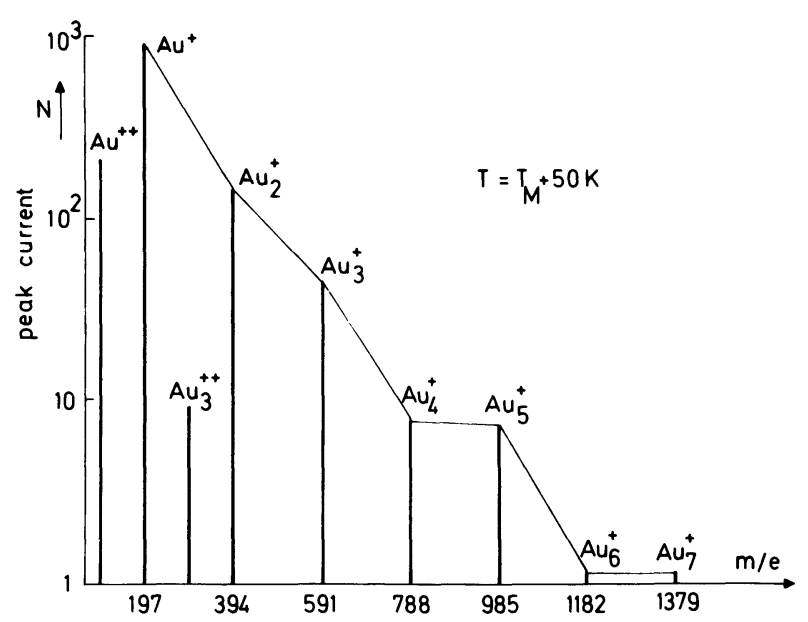

Fig. 2. - Mass distribution of the beam emitted by the EHD gold source. $T_{\mathrm{M}}=$ Melting temperature. $N$ in arbitrary units.

Though they constitute a minority fraction of the charge carriers in the ion beam, the molecular ions $\left(\mathrm{Au}_{2}^{+} \ldots \mathrm{Au}_{7}^{+}\right)$deserve some more detailed attention. Over a general and regular decrease of the signals when $n$ increases, one can detect slight oscillations : peaks with odd $n$ are relatively more intense than those with even $n$. This fact can be understood with the help of the theoretical predictions of Joyes [15] concerning the stability of noble metal clusters. As 
long as the equilibrium state of these clusters is considered, ions $\mathrm{Au}_{2 n+1}^{+}$with closed electronic shells are more stable than ions $\mathrm{Au}_{2 n}^{+}$with one unpaired electron. However these considerations deal with the final state of the cluster in the field free region and do not involve any information concerning the emission process.

3.2 ENERGy Distributions (Figs. 3 and 4). - The energy distributions for a number of emission products have been measured. The deficit scale is defined with respect to the applied voltage. One can extract three main conclusions from these energy deficit curves :

- for the two main species, $\mathrm{Au}^{+}$and $\mathrm{Au}^{++}$, the shape is roughly Gaussian with a long energy-deficit tail of weak intensity. FWHM of $65 \mathrm{eV}$ and $45 \mathrm{eV}$ respectively can be attributed to these ions;

- the energy distribution is narrower for multicharged ions. It can be checked either for $\mathrm{Au}^{++} v s$. $\mathrm{Au}^{+}$, or for $\mathrm{Au}_{3}^{++}$vs. $\mathrm{Au}_{3}^{+}$;

- the energy distribution of molecular ions is broad and secondary maxima of growing importance appear as $n$ increases.
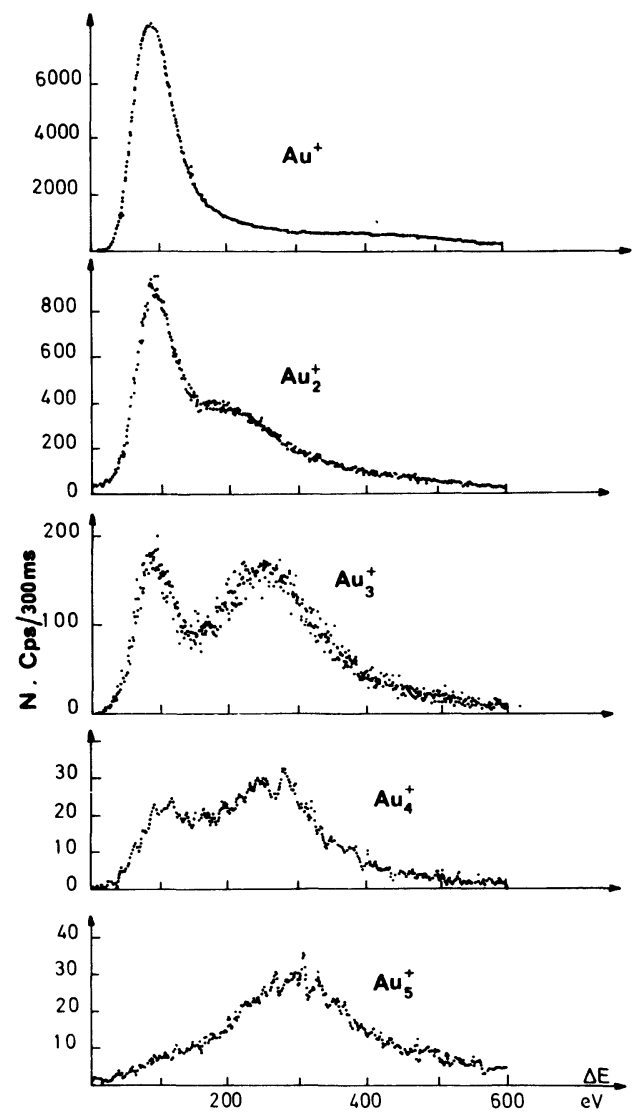

Fig. 3. - Evolution of the energy distribution for singly charged ions when $n$ increases.

4. Discussion and comments. - The mechanism of ion production in the EHD source has been primarily attributed to some thermal-assisted field evaporation process and the departures observed in the current-
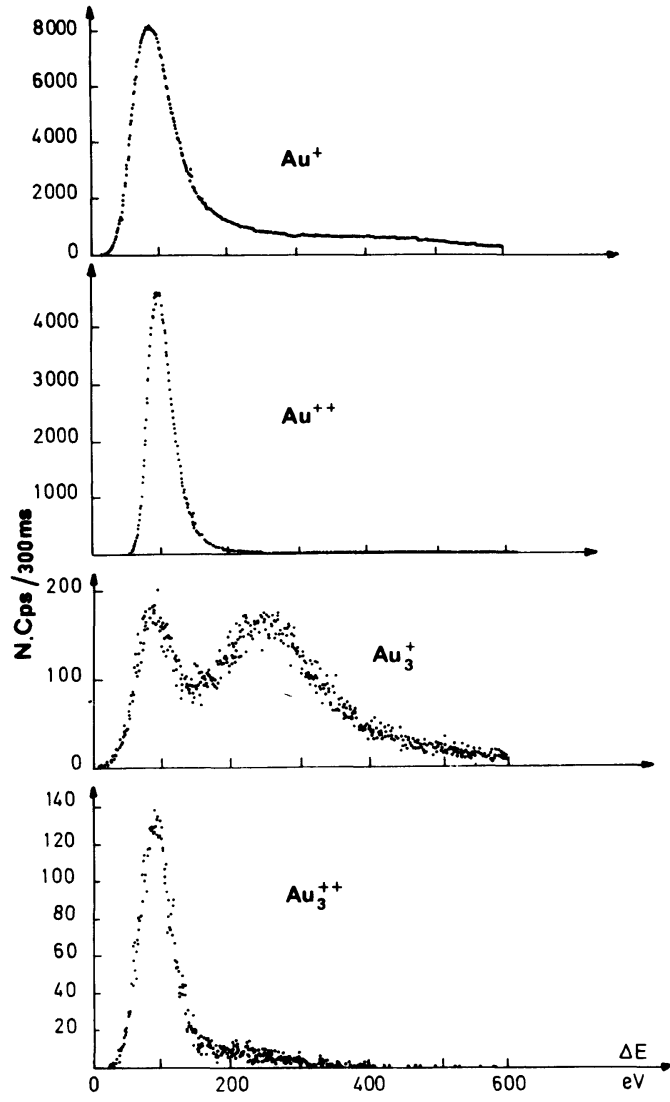

Fig. 4. - Comparison between the energy distributions of singly and doubly charged ions.

voltage characteristics were explained in terms of severe space-charge limitations. The failure of this model has been considered only recently, when suggestions were put forward, such as there is a small volume of intense ionization just outside the tip, formed by the interaction of ions and the locally dense vapour from the hot spot at the tip [6]. These ideas have been more clearly developed by Mair and von Engel [7] : Collisions in the vapour produce slow ions which pick up energy in the remaining part of the electric field. In this way an energy distribution of ions results.

The results reported here confirm these suggestions and provide the necessary experimental framework for the establishment of a more elaborate theory. The energy deficit is a clear indication of the localization of the ion production zone, since it measures the voltage drop between this zone and the metal surface. A large energy deficit corresponds to ion production at a rather large distance from the metal surface : following our estimation of the field strength close to the liquid metal apex in a schematic cone-sphere geometry, an energy deficit of $100 \mathrm{eV}$ means a distance of $2000 \AA$ from the surface. Therefore, in the emission regime which has been studied in this work, the ionization mechanisms are expected to take place in a high density plasma extending over thousands of Angströms from the liquid surface. 
In this plasma theory, collision and charge transfer processes are responsible for the ion production. The ionizing particles are likely electrons, for the ionization cross section for atomic gold is maximum for $100 \mathrm{eV}$ electrons and $5000 \mathrm{eV}$ ions. No ions with such an energy deficit could be detected in the beam, while an order of magnitude of $100 \mathrm{eV}$ is highly probable for the kinetic energy of the electrons impinging on the tip. On the other hand, the charge transfer mechanism between ions and neutrals is a likely event when the particle density is sufficiently high.

These considerations lead us to propose the model sketched in figure 5, which involves the existence of two main zones :

- A plasma zone, which is a few thousand Angströms thick. Ionization occurs by direct processes between electrons which fall towards the liquid metal and the emerging neutral aggregates, e.g. :

$$
\mathrm{Au}_{n}+\mathrm{e}^{-} \rightarrow \mathrm{Au}_{n}^{+}+2 \mathrm{e}^{-} .
$$

The high rate of neutral emission $\left(6 \times 10^{22} / \mathrm{cm}^{2}\right)$ is reached because of the local heating of the metal surface due to large Joule effects and to secondaryelectron bombardment (equivalent to an incident energy flux of $10^{6} \mathrm{~W} / \mathrm{cm}^{2}$ ). The narrower distribution of the $\mathrm{Au}^{++}$curve with respect to the $\mathrm{Au}^{+}$is a consequence of the higher ionization potential which requires greater kinetic energies for the impinging electrons : in the inhomogeneous field above the surface, this large kinetic energy can only be obtained by electrons arriving closer to the liquid.

- A charge transfer zone which extends over a larger distance from the surface. In this zone rearrangement processes can occur between the various components of the beam which are extracted from the plasma zone. Important ones allow charge transfers such as :

$$
\mathrm{Au}^{+}+\mathrm{Au}_{n} \rightarrow \mathrm{Au}_{n}^{+}+\mathrm{Au}
$$

without attachment, or :

$$
\mathrm{Au}^{+}+\mathrm{Au}_{n} \rightarrow \mathrm{Au}_{n+1}^{+}
$$

with attachment. These reactions could be responsible for the origin of the secondary peak in the energy

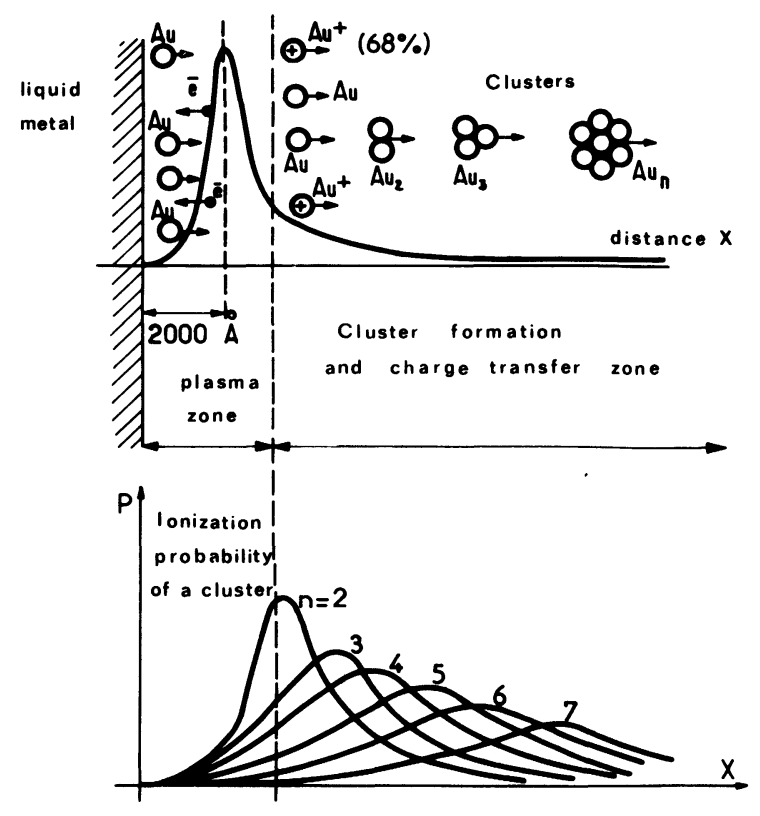

Fig. 5. - A plasma model proposed to explain the ionization mechanism in the EHD gold source.

distribution of molecular ions, and for its regular shift towards higher energy losses when the size of the cluster grows.

5. Conclusion. - Energy distribution measurements constitute a clear evidence of the occurrence of ionization processes in a plasma layer covering the liquid metal surface in the EHD process.

Though the necessary system of equations still remains to be written down and solved, the model which has been proposed above constitutes a starting point for further theoretical developments.

It must be kept in mind that all these results concern the EHD emission of gold ions. Rather strong differences can be expected for sources of lower melting point metals such as $\mathrm{Ga}$ or In, concerning the size of the extremity of a Taylor cone or the occurrence of a strong evaporation of neutrals from the surface.

Acknowledgments. - This research has been supported by grants DRME 76/1184 and DGRST 76/335. We acknowledge the fruitful help of P. Trebbia for the computer assisted recording of the spectra. 


\section{References}

[1] TAYLOR, G., Desintegration of Water Drops in an Electric Field, Proceedings of the Royal Society (London), Series A, Vol. 280, No 1382 (1964) 383-397.

[2] Swatik, D. S., Hendricks, C. D., AIAA Journal 6 (1968) 1596.

[3] Mahoney, J. F., Yahiku, A. Y., Daley, H. L., Moore, R. D., Perel, J., J. Appl. Phys. 40 (1969) 5101.

[4] Evans, C. A., Hendricks, C. D., Rev. Sci. Instrum. 43 (1972) 1527.

[5] Clampitt, R., Aitken, K. L., JefFeries, D. K., 21st International Field Emission Symposium (Marseille) 1974.

Clampitt, R., Jefferies, D. K., Inst. Phys. Conf. Ser. 38 (1978) 12.

[6] Krohn, V. E., Ringo, G. R., Appl. Phys. Lett. 27 (1975) 479.

[7] MaIR, G. L., von ENGel, A., 24th Int. Field Emission Symposium (Oxford) 1977.
[8] Seliger, P., 25th International Field Emission Symposium (Albuquerque) 1978.

[9] SwatiK, D. S., Rep. CPRL 3-69 (University of Illinois) 1969. [10] Sudraud, P., van de Walle, J., Colliex, C., Trebbia, P., 25th Int. Field Emission Symposium (Albuquerque) 1978.

[11] Colliex, C., Sudraud, P., van de Walle, J., Proc. 35th EMSA (Boston) (1977) 100.

[12] Tsong, T. T., Surf. Sci. 70 (1978) 211.

[13] Colliex, C., Sudraud, P., van de walle, J., Rep. DRME 76/1184 (Orsay) 1978.

[14] Trebbia, P., Ballongue, P., Colliex, C., Proc. 35th EMSa (Boston) (1977) 232.

[15] Joyes, P., J. Phys. Chem. Solids 32 (1971) 1369. 